\title{
O Papel do Psicólogo e das Entidades Junto a Crianças e Adolescentes em Situação de Risco
}

The role of the psychologist and of the entities with children and adolescent in risk situation

El papel del psicólogo y de las entidades junto a niños y adolescentes en situación de riesgo

Maria de Fátima Pereira Alberto, Daniela Rodrigues de Almeida, Luciana Chacon Dória, Priscylla Cavalcanti Guedes, Tâmara Ramalho de Sousa \& Wilker Luiz Pessoa de França

Universidade Federal da Paraíba

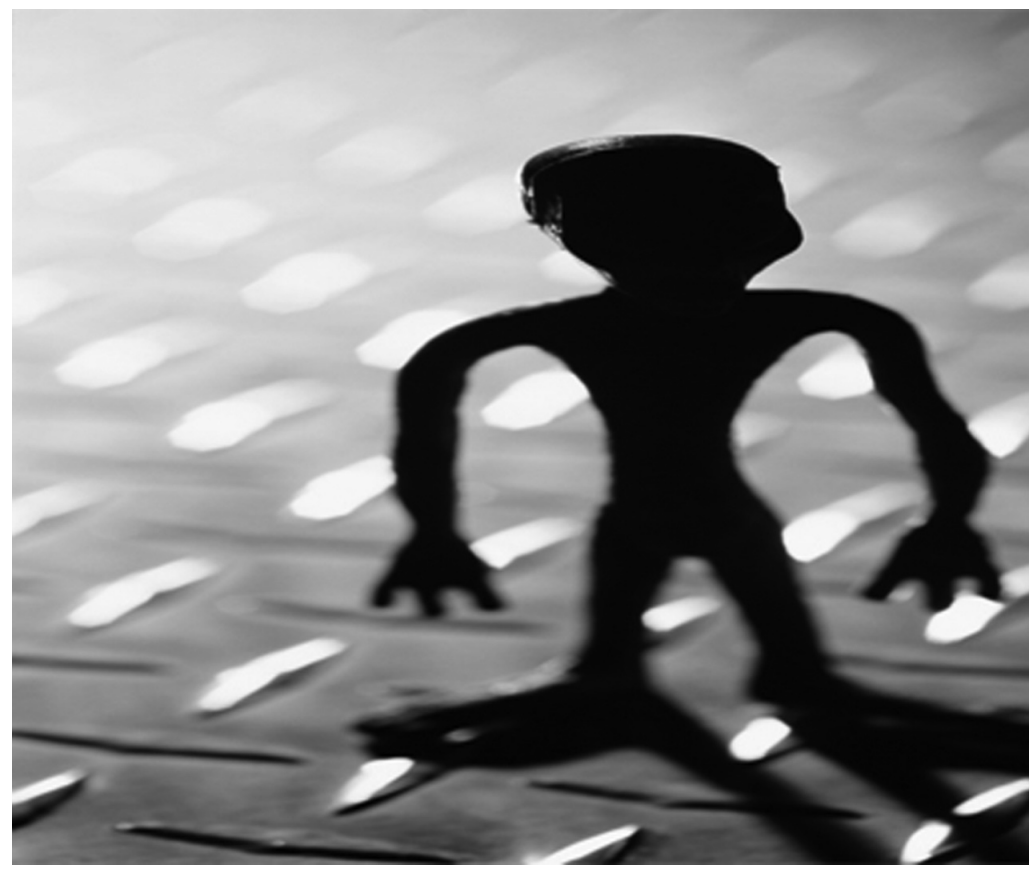


Resumo: Neste artigo, serão apresentados dados de uma pesquisa que objetivou identificar o tipo de trabalho desenvolvido por entidades e psicólogos responsáveis pelo atendimento de crianças e adolescentes em situação de risco. Foram realizadas 21 entrevistas semi-estruturadas com representantes e psicólogos dessas entidades. Na análise dos dados, utilizou-se a técnica de análise de conteúdo temático, de Bardin. As instituições investigadas atendem, em sua maioria, sujeitos de classe baixa, de 7 a 18 anos. Entre os tipos de trabalho desenvolvidos, estão atendimento jurídico, psicoterápico, médico-hospitalar e informativoeducacional. Os resultados demonstraram que há superposição de papéis entre organizações governamentais (OGs), Conselhos Tutelares e de Direitos e organizações não-governamentais (ONGs). Quanto ao trabalho desenvolvido pelos psicólogos nas instituições, sobressaiu a concepção fundamentada no modelo clínico e individual. Falta às instituições e aos psicólogos maior conhecimento do papel desse profissional junto às políticas públicas direcionadas a crianças e adolescentes em situação de risco.

Palavras-chave: Infância. Adolescência. Situação de risco. Papel do psicólogo.

Abstract: This article presents data from a research that intend to identify what kind of activity is developed by the psychologists and their entities who are responsible for taking care of children and adolescents in risk situation. In order to collect data, 21 semi-structured interviews were done with agents and psychologists of those entities. The data acquired by these interviews were categorized by the Bardin's analysis of thematic content. The majority of the individuals who are attended by the investigated institutions are from lower class and aged between 7 and 18 years old. Some of the activities developed by the institutions includes judicial, psychosocial, psychotherapist, medical and educational support. Throughout the results, it was possible to notice an overposition of roles among Governmental Organizations, Councils and Nom-Governmental Organizations. Regarding the activities developed in these institutions, a conception grounded in a clinical and individual model stood out. Both the institutions and psychologists are lacking in clarity on their role next to public policies directed to children and adolescents in risk situation.

Keywords: Childhood. Adolescence. Risk situation. Psychologist's role.

Resumen: En este artículo, serán presentados datos de una pesquisa que tuvo por objetivo identificar el tipo de trabajo desarrollado por entidades y psicólogos responsables por el servicio a niños y adolescentes en situación de riesgo. Fueron realizadas 21 entrevistas semi-estructuradas con representantes y psicólogos de esas entidades. En el análisis de los datos, se utilizó la técnica de análisis de contenido temático, de Bardin. Las instituciones investigadas atienden, en su mayoría, sujetos de clase baja, de 7 a 18 años. Entre los tipos de trabajo desarrollados, están el servicio jurídico, psicoterápico, médico-hospitalario e informativoeducacional. Los resultados demostraron que hay superposición de papeles entre organizaciones gubernamentales (OGs), Consejos Tutelares y de Derechos y organizaciones no gubernamentales (ONGs). En cuanto al trabajo desarrollado por los psicólogos en las instituciones, sobresalió la concepción fundamentada en el modelo clínico e individual. Falta a las instituciones y a los psicólogos mayor conocimiento del papel de ese profesional junto a las políticas públicas dirigidas a niños y adolescentes en situación de riesgo.

Palabras-clave: Infancia. Adolescencia. Situación de riesgo. Papel del psicólogo.

Neste artigo, serão apresentados dados de pesquisa cujo objetivo de investigação era identificar o tipo de trabalho desenvolvido pelas entidades responsáveis pelo atendimento dos direitos de crianças e adolescentes em situação de risco e que compõem o sistema de garantias do Município de João Pessoa. Outros objetivos eram identificar o tipo de trabalho feito pelo psicólogo nessas entidades, no contexto das políticas públicas de atendimento dos direitos de crianças e adolescentes, propiciar ao graduando em Psicologia o contato com a realidade e fornecer bases para a reflexão acerca do papel desse profissional no campo de trabalho em questão.

Desde a vinda dos exploradores portugueses até os dias atuais, a criança e o adolescente vivenciam experiências de violência, exclusão, abuso sexual e maus-tratos. Esse processo de violação começa em Portugal, com o recrutamento de crianças e adolescentes pobres, entre 9 e 16 anos, provenientes de orfanatos ou do rapto de crianças e adolescentes judias. Elas eram recrutadas 
A recuperação dar-se-ia não mais pelo simples encerramento em uma entidade de correção, mas sim, pela disciplina de uma entidade de caráter industrial: a pedagogia do trabalho

(Santos, 2002). para fazerem parte da tripulação das naus transoceânicas, pois assim se resolvia o problema dos investidores, comum à época, de manter um número grande de marinheiros em alto-mar, por um período prolongado de tempo. Os infantes consumiam menos alimentos do que os adultos e ainda os substituíam em várias tarefas, dentre as quais a preparação de alimentos e a limpeza dos navios. Em momentos de conflitos, ajudavam na recarga das armas, na limpeza das estrebarias e na alimentação dos animais (Ramos, 2002; Venâncio, 2002).

Durante a época da escravidão, o fato de ser criança não tirava do pequeno cativo a sua condição de escravo, filho de negro, que possuía uma curta infância a ser desfrutada. Sua força física e destreza ainda não eram suficientes para desempenhar certas atividades. Até aproximadamente os sete anos de idade, tinha o direito de acompanhar a mãe. Com sete ou oito anos, ela era incorporada aos comportamentos sociais, tanto no seu relacionamento com os senhores como naquele com a comunidade escrava. Também a partir dessa idade a criança estava suscetível aos castigos corporais e às humilhações (Góes \& Florentino, 2002).

No final do século XIX e no início do século $X X$, o processo de industrialização, aliado à imigração, dinamizava as cidades, nas quais se verificava a intensificação da divisão do trabalho. Mas o mesmo não se podia afirmar das condições sociais e habitacionais das cidades, com o crescimento dos cortiços, das pestes e das epidemias. Agravavam-se as crises sociais e avolumava-se a criminalidade decorrente das condições materiais e da interiorização da segurança. Diante dos elevados índices de delinqüência, buscava-se por vezes, na infância, a origem do problema. A recuperação dar-se-ia não mais pelo simples encerramento em uma entidade de correção, mas sim, pela disciplina de uma entidade de caráter industrial: a pedagogia do trabalho (Santos, 2002).
Um outro aspecto pertinente à história da criança e do adolescente excluídos surge a partir da Lei do Ventre Livre e se consolida no final dos anos 70 e início dos anos 80 . Trata-se da realidade dos meninos e meninas de rua; são crianças e adolescentes de ambos os sexos e de diferentes faixas etárias que passam a maior parte de seu dia nas ruas, dela retirando, através do trabalho formal, informal ou de atos ilícitos, o seu sustento ou o de sua família, embora possa não manter vínculo com esta. São frutos da estrutura social, econômica e política de um país "em desenvolvimento", cujos índices sociais beiram a miséria. Mas é também, por outro lado, um fenômeno psicológico, ou melhor, psicossocial, uma vez que diz respeito ao desenvolvimento de sujeitos que deveriam ter na família as bases psíquicas (afetivas, cognitivas e morais) e sociais (econômicas, materiais) para se estruturarem como adultos, serem humanos e cidadãos (Alberto, 2002).

Um outro fenômeno diz respeito à violência sexual, e esta pode ser evidenciada sob várias formas, com maneiras diferenciadas de expressão, tais como estupro, incesto, atentado violento ao pudor, abuso sexual e exploração sexual comercial, que pode acontecer, inclusive, no contexto familiar; a violência sexual, da mesma forma, data da vinda das primeiras caravelas, quando as meninas também eram recrutadas e enviadas para servirem de esposas aos portugueses nas colônias. Muitas delas recebiam abusos ainda nas embarcações. Embora um marco antigo na História, a violência de crianças e adolescentes torna-se um fenômeno social mais visível no Brasil após a realização da Comissão Parlamentar de Inquérito (CPI) da Prostituição Infanto-Juvenil, no ano 1993, e dos Congressos de Stocolmo, em 1996, e Yokohama, em 2001. Esses congressos produziram avanços conceituais e contribuíram para a elaboração de planos de ação e de enfrentamento não apenas no Brasil como também em outros países. 


\section{\begin{tabular}{l|l} 
As políticas públicas \\
voltadas para as crianças e os
\end{tabular} adolescentes}

No Brasil, há formas diferenciadas de a sociedade compreender e tratar as fases da infância e da adolescência, formas essas dependentes das categorias sociais a que eles pertençam. Referimo-nos a um processo de socialização desigual, pautado em classes sociais. Mannheim (1968) denomina essas fases de desenvolvimento de "prolongadas" ou "abreviadas". A relação da infância e da adolescência com a sociedade é desigual: não há a existência de uma infância e de uma juventude para todos. Desse modo, aqueles pertencentes às classes dominantes vivenciam um desenvolvimento prolongado, enquanto os que pertencem às classes dominadas, de baixo poder aquisitivo, têm um desenvolvimento abreviado.

No século XIX, foram criadas as Casas de

Educandos e Artífices, voltadas para as crianças e os adolescentes das classes

populares, sob o pretexto de se diminuir a criminalidade e vagabundagem, e os Asilos da Infância

dos Menores Desvalidos, para recolher órfãos e encaminhá-los às oficinas públicas e particulares, onde deveriam receber instrução primária e aprender ofícios mecânicos

(Pillotti, 1995).
A história da infância (e da concepção de infância) das classes populares no Brasil variou conforme o desenvolvimento das forças produtivas. Segundo Londoño (1991), do século XVII ao XIX, alteraram-se as representações sociais sobre essas crianças e as formas de lidar com o problema de que eram vítimas - órfãs, enjeitadas, abandonadas e carentes. No século XVIII, predominava o "sentimento de pena" e o reconhecimento da necessidade de oferecer abrigo, proteção e educação através de entidades caritativas que pudessem preencher, em parte, as lacunas daqueles que tinham sido privados do convívio familiar. No século XIX, o Estado usou como medida "ações disciplinares", segundo as quais crianças que ocupavam as ruas eram compreendidas como caso de polícia, devendo ser julgadas e enviadas às casas de detenção para serem "punidas" e "recuperadas".

No século XIX, foram criadas as Casas de Educandos e Artífices, voltadas para as crianças e os adolescentes das classes populares, sob o pretexto de se diminuir a criminalidade e vagabundagem, e os Asilos da Infância dos Menores Desvalidos, para recolher órfãos e encaminhá-los às oficinas públicas e particulares, onde deveriam receber instrução primária e aprender ofícios mecânicos (Pillotti, 1995).

No período republicano, os antigos asilos foram se transformando em institutos, escolas profissionais, patronatos agrícolas, reformatórios e escolas premunitórias e corretivas. Configurava-se, assim, o trabalho como um antídoto contra a marginalidade.

No século XX, a conjuntura institucional, aliada a agravantes socioeconômicos, originou uma nova representação social contra essas crianças e adolescentes das classes populares que ocupavam as ruas das grandes cidades. Esses "menores abandonados" passaram a ser vistos como "menores infratores" que precisavam de reclusão e reeducação, cabendo ao Estado a responsabilidade de criar e manter entidades capazes de afastá-los da comunidade, auxiliando-o, assim, a manter a ordem pública.

O Código de Menores promulgado em 1927 é caracterizado por Cassab (2001) como a primeira resposta mais consistente à presença incomodativa dos jovens pobres. Incorporava tanto uma visão higienista de proteção do meio e do indivíduo como a visão jurídica repressiva e moralista.

No que se refere à assistência pública, o "menor", que vinha sendo tratado pela esfera jurídica através dos Juízes de Menores e pela atuação isolada de alguns estabelecimentos, com o Estado Novo, passou a ser tratado pelo Serviço de Assistência ao Menor (SAM), pelo Departamento da Criança (DNCr) e pela Legião Brasileira da Assistência Social (LBA). Em tempos posteriores, datados pelo contexto repressivo da ditadura militar, foi criada a 
Fundação Nacional de Bem-Estar do Menor (FUNABEM), que se propunha a assegurar prioridades aos programas que visassem à integração do menor na comunidade, através de assistência na própria família e da colocação familiar em lares substitutos, mas que acabou se moldando à tecnocracia e ao autoritarismo e se configurando como meio de controle social em nome da segurança nacional.

As experiências de controle social da FUNABEM contribuíram para a reformulação do Código de 1927, que dá lugar ao Código de Menores de 1979, que recebeu não somente a inspiração da teoria menorista da situação irregular mas também do regime totalitarista e militarista, então vigente no País, e manteve essas concepções, apesar de elaborado já sob a influência da Declaração dos Direitos da Criança, de 1959.

O fracasso das entidades fechadas, aliado “...repúdio ético e político de setores da sociedade" (Costa, 1990, p. 20) sensíveis à questão dos direitos humanos, fez com que o Código do Menor desse lugar, no final da década de 1970, ao Plano de Integração Menor - Comunidade (Plimec), cujos objetivos eram o de atender a crianças e adolescentes em seu meio de origem e o de evitar que a necessidade de sobrevivência impulsionasse os meninos para a rua. Foram abaixo a padronização e o verticalismo do Plano Integrado Menor Comunidade - Plimec, que não se coadunavam com as realidades regionais.

A década de 1980, marcada pela eclosão de movimentos de contestação na sociedade brasileira, que emergiram com o fim do regime militar, produziu uma nova postura no processo de conscientização quanto às crianças e aos adolescentes em situação de risco pessoal e social. O termo risco foi associado aos estudos sobre desenvolvimento humano (Horowitz, 1992). Por situação de risco pessoal e social, entende-se a condição em que se encontram crianças e adolescentes que, "por suas circunstâncias de vida, estão expostas à violência, ao uso de drogas e a um conjunto de experiências relacionadas a privações de ordem afetiva, cultural e socioeconômica que desfavorecem o pleno desenvolvimento biopsicossocial" (Lescher, 2004, p. 11).

Na década de 1980, surge um movimento de defesa dessas crianças que culminou, em 1985, na constituição do Movimento Nacional de Meninos e Meninas de Rua, organização da sociedade civil, que se tornará o marco e o baluarte pela defesa dos direitos desses pequenos cidadãos. Em 1986, o Movimento promoveu o I Encontro Nacional de Meninos e Meninas de Rua. Em 1988, criou-se o Fórum Nacional Permanente de Entidades Não-Governamentais de Defesa dos Direitos da Criança e do Adolescente, que mobilizou várias organizações pró-constituinte, e que, juntos, elaboraram o projeto de que resultou a Lei no 8.069/1990, denominada Estatuto da Criança e do Adolescente.

Segundo Costa (1990), o Estatuto da Criança e do Adolescente (ECA) traz um novo ordenamento jurídico para a questão da infância e da juventude, e este, por sua vez, introduz basicamente três tipos de inovação na política de promoção e defesa de direitos:

Mudanças de conteúdo - introduz novos conteúdos de ações e de políticas de atendimento, como defesa jurídico-social, assistência médica e psicossocial às crianças e adolescentes vitimizados, além de agrupar e hierarquizar as políticas.

Mudanças de métodos - substitui as práticas assistencialistas e correcionais-repressivas por práticas socioeducativas. No Judiciário, substitui a doutrina da situação irregular pela concepção garantista, que cria salvaguardas 
jurídicas que asseguram o respeito à condição de sujeitos de direitos.

Mudanças na gestão - O Estatuto assegura a participação popular, por meio de suas entidades representativas, a formulação das políticas e o controle das ações.

O ECA, concebido como a doutrina da proteção integral, determina a forma de atuação das entidades governamentais e nãogovernamentais no atendimento à criança e ao adolescente e que, segundo o Artigo 86, dar-se-á mediante um conjunto articulado de ações governamentais e não-governamentais, da União, dos Estados, do Distrito Federal e dos Municípios.

No Artigo 87 do ECA, são traçadas as linhas de ação da política de atendimento: políticas sociais básicas, políticas e programas de caráter supletivo para os que dela necessitarem, serviços especiais de prevenção e atendimento médico e psicossocial às vítimas de negligência, maus tratos, exploração, abuso, crueldade e opressão, serviço de identificação e localização de pais e responsáveis, crianças e adolescentes desaparecidos e proteção jurídico-social por entidades de defesa dos direitos da criança e do adolescente. É nesse contexto da política de atendimento que tem lugar o papel do psicólogo.

A consolidação, na Constituição Federal, da Doutrina da Proteção Integral regulamenta, além do ECA, outras políticas setoriais, como o Sistema Único de Saúde - SUS, a Lei Orgânica da Assistência Social - LOAS e a Lei de Diretrizes e Bases da Educação - LDB. São políticas que têm como princípios comuns a descentralização política e administrativa e a participação da sociedade.

A organização dessa assistência está prevista na LOAS (Lei no 8742/93). Na referida Lei, o atendimento assistencial é concebido como proteção social básica e proteção social especial (esta última dividida em média complexidade e alta complexidade). A proteção social básica trata daquilo que é um direito universal, de todos. A proteção social especial é a modalidade de atendimento assistencial destinada a pessoas ou grupos que se encontram em situação de risco pessoal ou social.

A idéia de que as políticas sociais básicas são imprescindíveis para assegurar a proteção integral levaram os Conselhos de Direitos a assumirem a tarefa de operar uma linha de ação no sentido de articular um sistema de garantia de direitos para enfrentar as violações sofridas por crianças e adolescentes, sobretudo aquelas em situações de risco pessoal e social (CONANDA, 2000). Essa articulação comporta a promoção, a defesa e o controle social.

A promoção visa à realização do Direito. Fazem parte do eixo: setores públicos (gestores da saúde, educação, assistência social), Conselhos de Direitos da Criança e do Adolescente e Conselhos Setoriais (assistência social e educação). A defesa visa à responsabilização no caso de omissão, falta ou oferta irregular dos Direitos por parte da família, do Estado ou da sociedade. Fazem parte do eixo: o Ministério Público, o Ministério do Público do Trabalho, o Conselho Tutelar, o Judiciário, a Defensoria Pública e os Centros de Defesa de Direitos Humanos. O controle social visa ao acompanhamento e à fiscalização do cumprimento dos direitos. Fazem parte do eixo as entidades da sociedade civil, articuladas ou não (Cabral, 1999).

\section{A atuação do psicólogo nas políticas públicas para crianças e adolescentes}

Para fazer frente às situações de risco, as políticas públicas de assistência social precisam do trabalho de profissionais de vários setores, tais como saúde, educação, assistência social e sistema de Justiça. Dentre as áreas de atuação, 
demandam-se, dentre outros profissionais, os de assistência social e da Psicologia. O ECA traz, para o profissional de Psicologia, papéis a serem desempenhados nas políticas públicas de atendimento dos direitos da criança e do adolescente.

Sob o paradigma da proteção integral, o juiz não atua mais com exclusividade. Há um reordenamento do atendimento à criança e ao adolescente, uma interdisciplinaridade de profissionais. E a família constitui o foco principal. O papel do psicólogo não é mais o de técnico que só atua do ponto de vista do conhecimento específico, principalmente dos testes. O papel do psicólogo agora é a atenção na proteção integral, e ele deve considerar a criança e o adolescente sujeitos de sua história, sujeitos de direitos, protagonistas; tem que atuar em rede, interdisciplinarmente (Conselho Federal de Psicologia, 2003).

Dentro da concepção da proteção integral, o papel do psicólogo no sistema de garantias, junto ao de outros profissionais, passa, então, a ser o de um viabilizador de direitos, devendo para tal ter conhecimento profundo da legislação, uma vez que a descentralização Ihe exige novas e capacitadas competências, a autonomia política administrativa impõe a participação, e o controle requer um arcabouço teórico-técnico-operativo que visa ao fortalecimento de práticas e espaços de debate, na propositura e no controle de política na direção da autonomia e do protagonismo dos usuários, assim como nas relações entre gestores, técnicos das esferas governamentais, dirigentes e técnicos, prestadoras de serviços, conselheiros e usuários. Mas a atuação desses profissionais deve se dar em rede, ou seja, em complementaridade técnica (Ministério do Desenvolvimento Social, 2004).

Para o Conselho Nacional dos Direitos da Criança e do Adolescente (CONANDA), "Ao nos integrarmos nessa rede, vamos nos tornando importantes socialmente e vamos nos tornando necessários para que essa rede funcione plenamente" (Conselho Federal de Psicologia, 2003, p. 194).

Para Teixeira e Novaes (2004, p. 293), "ampliase o objeto de intervenção do psicólogo, que passa a abarcar aspectos da vida concreta, cotidiana e seus efeitos na configuração de subjetividades", que são produzidas e realimentadas no entrelaçamento dos indivíduos entre si e com as entidades.

Na operacionalização do sistema de garantias, a atuação do psicólogo dar-se-á nos seguintes eixos: análise da situação, no sentido de diagnosticar a realidade através de pesquisas que possibilitem a análise e o planejamento de ações e recursos para o enfrentamento das situações de risco, mobilização e articulação dos vários segmentos (governamentais, nãogovernamentais, sociedade civil nos níveis nacionais, regionais e locais), promoção, defesa e responsabilização através de mecanismos de exigibilidade dos direitos e humanização dos serviços, promoção, atendimento e prevenção através de ações especializadas de atendimento, com a inclusão social das crianças, adolescentes e suas famílias e promoção de ações que possibilitem aos jovens o empoderamento dos mesmos com vistas ao protagonismo social.

As novas demandas para a atuação do psicólogo nas políticas sociais para crianças e adolescentes requerem um profissional multifunções, que trabalhe de forma interdisciplinar e em rede. Mas esse novo modelo, que emerge a partir da Constituição Federal de 1988 e do Estatuto da Criança e do Adolescente, documentos que garantiram àqueles a condição de sujeitos de direitos, não foi suficiente para dar conta da discussão, antiga na Psicologia, realizada por diversas correntes que discutem o modelo de Psicologia adequado às classes trabalhadoras, às populações marginalizadas, às populações sem a experiência da escolarização e às comunidades pobres. 
Dentre as várias visões sobre esse modelo de atuação, destacam-se, neste artigo, os estudos de Bock (2003); Gonzáles-Rey (2001); Guattari e Rolnik (1986); Ropa e Duarte (1985).

Ropa e Duarte (1985) discutem a questão do atendimento psicológico às classes trabalhadoras. Eles situam a discussão no contexto dos limites sociais e culturais do modelo clínico (psiquiátrico-psicológico) e da sua eficiência para as classes trabalhadoras. Segundo os citados autores, "a constituição das ciências psicológicas representaria, nesse sentido, o apogeu da progressiva segmentação individualizante: um saber autônomo sobre sujeitos autônomos" (p. 193). Nessa perspectiva, confrontam-se grupos portadores de visões de mundo mais "individualizantes" e visões mais "holistas", visões "mais modernas" e visões "mais tradicionais", grupos de "camadas urbanas" e de "camadas mais periféricas". Segundo os autores, "inscreve-se um modelo patologizante, individualizante, que, dentro de uma visão etnocêntrica, se pretende universal, missionária e civilizadora, que nega qualquer singularidade. E que, na prática, parece enfrentar a resistência de sujeitos "não-individualizados" ou sujeitos que resistem "à ideologia individualista dominante" (p. 201).

Guattari e Rolnik (1986), embora não façam uma discussão na perspectiva do modelo adequado para as diferentes classes sociais, ao tratarem dos dispositivos de singularização, concebem a psicanálise como um desses dispositivos de subjetivação, que preconiza modelos de identidade ou de identificação. Concebem ainda que os profissionais trabalham sistematicamente na consolidação de certa produção de subjetividades. Em vez desse modelo, os referidos autores propõem a liberdade de construção de novos tipos de modelo referentes à análise, e, para isso, fazem uso do conceito de transversalidade, ou seja, propõem uma relação de horizontalidade a partir da qual se criariam conexões inimagináveis, múltiplas, que constroem sentidos singulares, sem homogeneizá-los através de ditames universais.

González-Rey (2001) faz uma crítica ao que denomina referencial hermético da clínica, "que parte de princípios fundadores únicos e universais" (p. 194). Concebe a clínica como "um diálogo no qual os conhecimentos marcam as formas de participação do terapeuta" (p. 195), o que, para ele, cria um paradoxo, porque, para o exercício terapêutico, ele precisa afastar-se desse referencial para poder visualizar o sujeito singular. O referido autor afirma que o papel do psicólogo, nesse diálogo, que é uma via de mão dupla, é compreender que o sujeito gera novos sentidos e espaços de subjetivação, e isso pode implicar a integração de diversos protagonistas ou o deslocamento do psicólogo nesses espaços, familiares ou institucionais.

Bock (2003) apresenta, na obra por ela organizada, uma visão atualmente enfatizada em relação à atuação do psicólogo nas políticas sociais. Trata-se da concepção do compromisso social, definida pelo papel de construir teorias e práticas na direção da transformação social, do compromisso com (o que autoconceituam como) as camadas populares e com uma psicologia dialética que olha e atua, a partir do contexto, na participação política, nos espaços de confronto em defesa dos direitos dos cidadãos.

\section{Metodologia}

A pesquisa foi feita como uma prática da disciplina Psicologia do Desenvolvimento II, por isso antecedeu à sua realização a preparação dos alunos, que consistiu, inclusive, na realização de nove seminários sobre as seguintes temáticas: Vulnerabilidade e Drogas, Trabalho Infantil, Gravidez Precoce, 
DSTs e Aids, A Criança e o Adolescente no Brasil: da Situação Regular ao Sujeito de Direito, Meninos e Meninas em Condição de Rua, Abuso Sexual Infanto-juvenil, Exploração Sexual Comercial e Adolescentes em Conflito com a Lei.

Cada temática ficou a cargo de um grupo de alunos da disciplina. Cada grupo ficou responsável pela visitas e entrevistas a três entidades. Portanto, conforme descrito acima, foram realizados nove seminários, logo, deveriam ter sido investigadas 27 entidades. Todavia houve casos em que só foi possível realizar duas entrevistas devido a dificuldades de acesso a algumas entidades.

Foram realizadas entrevistas, nos meses de junho e julho de 2006, com 21 instituições da cidade de João Pessoa. Todas as instituições trabalham no atendimento de crianças e de adolescentes em situação de risco e compõem o sistema de garantias, nos eixos de promoção, defesa e controle, caracterizadas como: sistema de Justiça, organizações governamentais, ONGs e Conselhos (tutelares e de direitos).

A escolha das entidades participantes da pesquisa recaiu, por um lado, naquelas que atuavam no atendimento de crianças e adolescentes expostas às situações de risco pessoal e social que haviam sido tratadas nas temáticas abordadas nos seminários da disciplina, e, por outro, naquelas com as quais o Grupo de Estudos sobre o Trabalho Precoce tinha tido contatos ou articulações anteriormente.

Utilizou-se a metodologia qualitativa, que contempla a fala como elemento de significação dos dados. O instrumento usado foi uma entrevista semi-estruturada, com questões abertas e fechadas, contendo duas partes: uma, que seria respondida pelos dirigentes ou responsáveis, e a outra, que seria respondida pelos psicólogos que trabalham na referida entidade.

Participaram da pesquisa 18 dirigentes ou responsáveis e 13 profissionais de Psicologia. Houve instituição em que só o dirigente respondeu, outras em que apenas o profissional de Psicologia respondeu. E houve instituições em que não havia psicólogos.

As questões versavam sobre a atuação das entidades e o papel do psicólogo nessas entidades. O primeiro aspecto abrange a faixa etária e as condições econômicas da população atendida, o tipo de entidade, a demanda populacional, o objetivo e o tipo de trabalho desenvolvido, a metodologia do trabalho, as dificuldades e as necessidades enfrentadas. A segunda parte abordava a presença ou o motivo da ausência do profissional de Psicologia na entidade, o papel do profissional de Psicologia na entidade, o tipo de trabalho desenvolvido, os procedimentos utilizados, as dificuldades e as facilidades quanto à realização do trabalho.

Após a realização das entrevistas e a apresentação em sala de aula, que visava a atingir os objetivos expressos na introdução deste artigo, um grupo de alunos se responsabilizou pela análise das mesmas, submetendo-as à análise de conteúdo de Bardin (1977). Para tal, utilizou-se a técnica de análise de conteúdo temático, enfatizando-se a ausência ou a presença do tema a despeito de sua freqüência. Procedeu-se à tabulação, com a finalidade de se fazer o recorte das unidades temáticas, à codificação, com a finalidade de agrupar o recorte das unidades temáticas para a construção das categorias, à categorização, com a finalidade de elaborar uma representação simplificada do conteúdo, e, por fim, à inferência e à interpretação, com as finalidades de descrever os dados e estabelecer relações com os fundamentos teóricos adotados. 


\section{Resultados}

\section{Faixa etária atendida pela entidade}

As faixas etárias das crianças e adolescentes atendidas pelas entidades podem ser classificadas da seguinte forma: de 0 a 12 anos, de 7 a 18 anos e de 7 a 35 anos. Este último é um caso específico de uma entidade que presta atendimento, trabalhando tanto com crianças e adolescentes quanto com adultos e idosos.

\section{Condição socioeconômica da população atendida}

Quanto às condições socioeconômicas, as crianças e adolescentes atendidos são, segundo os participantes da pesquisa, em sua grande maioria, de "classe baixa". Apenas uma pequena parcela das entidades atende às classes baixa e média, e apenas uma entidade respondeu não haver distinção socio-econômica entre o público atendido, pois tanto é procurada para o atendimento a crianças e adolescentes de classe baixa como de classe média e alta.

\section{Demanda atendida}

Quando indagadas sobre a demanda, as entidades responderam classificando-a qualitativamente e quantitativamente. Em relação à primeira categoria, foram incluídas as seguintes subdivisões: quanto ao tipo de risco (maus tratos, usuários de drogas, crianças que trabalham, abuso e exploração sexual), quanto ao perfil dos jovens atendidos, que foi relacionado à idade e ao sexo, e outras ainda afirmaram atender uma clientela de retaguarda, ou seja, atendem crianças e adolescentes encaminhados de outras entidades. A classificação quantitativa referese ao número de ocorrências diárias, semanais ou mensais. Nesse último caso, não se versará, neste artigo, sobre essa classificação, uma vez que as formas de registro são heterogêneas, sem a possibilidade de análises comuns. Um outro aspecto ressaltado pela maioria das entidades é que elas são procuradas, não fazem busca ativa.

\section{Caracterização do tipo de atendimento institucional}

A resposta ao item da entrevista como se caracteriza o trabalho desenvolvido pela entidade era do tipo múltipla escolha, que admitia mais de uma resposta e continha a categoria outros. Dessa forma, houve entidades que prestavam mais de um tipo de atendimento. O trabalho da maioria das entidades se caracteriza por atendimento jurídico (10). Foram relatados também atendimentos psicossociais (09), assistenciais (09), psicoterápicos (07), médico-hospitalares (06), informativo-educacionais (05), psicológico (01) e proponente e fiscalizador (01), sendo os três últimos pertencentes à categoria outros.

\section{A metodologia do atendimento nas entidades}

Percebeu-se que o sistema de Justiça atua através do sentenciamento, do acompanhamento de sentenças, do acompanhamento de medidas e do encaminhamento para outras entidades. As entidades governamentais, até pelo fato de serem em maior número, apresentaram uma abrangente variabilidade, desde gestão, fiscalização do trabalho infantil, fiscalização e monitoramento de políticas até formação profissional, escolarização, capacitação de profissionais, formação e qualificação profissional de adolescentes, atividades de arte e cultura, recebimento de denúncias e visitas domiciliares, acompanhamento jurídico, conscientização e planejamento familiar. 
As ONGs trabalham através de oficinas, debates, seminários, distribuição de preservativos, intervenções na comunidade e trabalho em rede. Os Conselhos Tutelares trabalham com a averiguação da denúncia, o aconselhamento psicológico e o encaminhamento. Os Conselhos de Direito atuam através de discussões políticas com as entidades e encaminham solicitações para a prefeitura através de proposituras para os gestores.

Ao caracterizarem a metodologia de trabalho adotada pelas entidades, constatou-se um aspecto significativo, ou seja, a caracterização de práticas específicas do profissional da Psicologia, que eram referenciadas pelas entidades como a sua forma de atuação. Essas categorias temáticas emergiram dentre aquelas que atuaram através de acompanhamento e atendimento psicossocial (tanto à criança e ao adolescente como às famílias), aconselhamento, psicoterapia, avaliação psicológica; já quanto àquelas que compõem o sistema de Justiça, não foi feita referência à atuação do psicólogo como forma de atuação das entidades.

\section{Objetivos do trabalho}

Quando indagados sobre os objetivos, as respostas se deram em um conjunto de elementos que possibilitaram a seguinte categorização temática: oferecer saúde preventiva e educação sexual a adolescentes, prestar atendimento a crianças vítimas de abuso, executar o plano nacional de enfrentamento da violência sexual, encaminhar sentenças a outras entidades, fiscalizar outras entidades, ressocializar o jovem e promover o cuidado da criança e do adolescente e zelar por seus direitos.

Ao se analisar essas respostas, percebe-se que as entidades se definem tendo como função:

(a) promoção ou realização do direito, (b) responsabilização e (c) acompanhamento e fiscalização no cumprimento dos direitos. Embora as entidades se definam como defensoras e cumpridoras dos direitos de crianças e adolescentes de modo geral e incluam a prevenção entre os seus objetivos, na prática, a atuação da maioria delas é voltada para crianças e adolescentes que se encontram em situação de risco, ou seja, aqueles que, devido às suas circunstâncias de vida, estão expostos à vulnerabilidade e cujos direitos já foram violados.

\section{Dificuldades enfrentadas pela entidade}

As dificuldades encontradas foram classificadas da seguinte forma: (a) infra-estruturais, referentes ao espaço físico, escassez de recursos financeiros, transportes e diárias; (b) culturais, relativas às crenças e tabus presentes na sociedade e que dificultam o trabalho da entidade; (c) familiares, englobando a reincidência do adolescente, a descontinuidade do trabalho e a pouca participação dos pais bem como a pouca possibilidade de estabelecer vínculos com as crianças e adolescentes; (d) falta de equipamento institucional, que corresponde à retaguarda (ausência de emprego para os jovens, falta de apoio dos órgãos públicos e falta de geração de renda para a família), (e) falta de articulações entre as entidades, que se referem à inexistência de um sistema de redes entre elas; (f) falta de uma equipe técnica, em relação à quantidade e à formação especializada para atuar nas temáticas (DSTs e Aids, vulnerabilidade e drogas, gravidez precoce, trabalho infantil, meninos e meninas em condição de rua, abuso sexual infantojuvenil, exploração sexual comercial e medidas socioeducativas).

\section{O que poderia ser feito para facilitar o trabalho da entidade}

Quanto ao que poderia ser feito para se facilitar o andamento do trabalho, as respostas 
resultaram em um conjunto de elementos que possibilitaram a seguinte categorização temática: ter uma equipe mais ampla e mais bem capacitada, melhor infra-estrutura, maior divulgação do trabalho das entidades, maior apoio dos órgãos públicos e uma padronização do atendimento no sentido de um trabalho contínuo e em rede das entidades.

\section{Presença de psicólogo na entidade}

Em 18 das 21 entrevistas, foi encontrada a resposta afirmativa ao item "Há psicólogo na entidade?". Após essa questão, perguntouse aos representantes qual seria o papel do psicólogo nessas. Das respostas, surgiu um conjunto de elementos que possibilitaram a seguinte categorização temática: que esse profissional pode desenvolver mais de uma atividade de trabalho em uma mesma entidade. Uma parcela respondeu que o psicólogo tem o papel de atender através de psicoterapias individuais (06); outra respondeu ainda que desenvolvem o trabalho de escuta (05), aconselhamento (05), informativo-educativo (05), encaminhamento (03), psicoterapia em grupo (02), oficinas (01), acompanhamento psicológico dos profissionais (01) e acompanhamento de sentenças (01). Percebe-se que, na maioria das entidades, o papel dos psicólogos se restringe a uma atuação clínica com uma intervenção de caráter individual.

Para aquelas que não possuíam psicólogo, foi indagado qual o motivo. Uma delas disse ser necessário valorizar a função e o profissional, e outra afirmou ser um problema de gestão e uma questão de cultura, por não se valorizar e priorizar a ação desse profissional nas entidades. Quando indagadas sobre se havia necessidade desse profissional, todas afirmaram que sim.

\section{O papel do psicólogo nas entidades que atuam com crianças e adolescentes em situação de risco}

Na entrevista semi-estruturada, houve também perguntas dirigidas aos psicólogos das próprias entidades. A primeira delas dizia respeito ao tipo de trabalho desenvolvido. As respostas possibilitaram a seguinte categorização temática: os profissionais fazem, em sua maioria, atendimento psicoterápico individual (06), aconselhamento (04), psicoterapia em grupo (04), trabalho educativo-informativo (03), escuta (02), oficinas (02) e visitas domiciliares.

\section{Dificuldades enfrentadas pelos psicólogos}

Os psicólogos responderam também sobre as dificuldades enfrentadas em seu trabalho. Mais uma vez, a dificuldade infra-estrutural (falta de espaço físico) foi a que esteve mais presente. Duas outras dificuldades mencionadas merecem destaque: a descontinuidade por parte da clientela, ou seja, o não comparecimento das crianças e adolescentes devido a causas individuais e familiares e a questão financeira, por parte das entidades. Observando-se as demais respostas, foram encontradas as dificuldades culturais (tabus e preconceito sobre a temática da sexualidade e falta de entendimento dos funcionários da entidade do papel do psicólogo) e políticas (falta de parcerias), além da insuficiência de profissionais para as atividades.

Os psicólogos disseram que, para facilitar o andamento do seu trabalho, deveria haver uma maior viabilização do sistema de garantias - ou seja, uma comunicação mais efetiva entre órgãos públicos e entidades e uma ampliação da equipe profissional, tanto em quantidade quanto em especialidades. 
Compreendem ainda que se faz necessária também maior participação dos jovens e de suas famílias, além de melhorias financeiras da entidade e educativas (visando a uma desconstrução de tabus e estereótipos).

\section{Discussão}

A identificação das faixas etárias atendidas pelas entidades revela que parte delas é responsável pela área de saúde preventiva e atende a população em geral, com ênfase em crianças e adolescentes; as que compõem o sistema de Justiça atendem adolescentes, e os Conselhos e entidades que exercem função de defesa prestam atendimento tanto a crianças como a adolescentes.

Como se trata de entidades do sistema de garantias, deveriam atender crianças e adolescentes indiscriminadamente, de todas as condições econômicas ou classes sociais, mas, como a escolha das entidades se baseou em algumas situações de risco, conforme descrito na metodologia, o que as entidades dizem é que a demanda de risco vem do que conceituaram como "classes baixas", que seriam as mais vulneráveis em relação às temáticas tratadas, o que pode levar à inferência de que essas são as mais demandantes das políticas públicas, uma vez que as outras classes sociais teriam outras retaguardas. Tais demandas aqui identificadas só vêm confirmar o que determina a LOAS (Ministério da Previdência e Assistência Social, 2001), de que o atendimento assistencial é imprescindível para assegurar a proteção integral e garantir direitos a crianças e adolescentes em situação de risco, que são sujeitos em processo de desenvolvimento que deveriam ter acesso a políticas sociais básicas para terem os seus direitos fundamentais garantidos. Mas o que se pode deduzir, a partir dos dados embasados nos referenciais teóricos preconizados pelo ECA (Ministério do Desenvolvimento Social, 2004) e pela LOAS (Ministério da Previdência e Assistência
Social, 2001), é que essas entidades atuam nas políticas de proteção social especial, ou seja, na modalidade de atendimento assistencial destinada a pessoas ou grupos que se encontram em situação de risco pessoal ou social; as entidades e os psicólogos, dessa forma, atuam nas medidas de proteção concebidas no ECA (Art. 98) e aplicáveis sempre que os direitos forem ameaçados ou violados.

Na forma de atuação das entidades, prevalecem, no sistema de Justiça, ações de execução de sentença, que demarcam também certo território de ações no qual o trabalho do psicólogo não aparece como componente; são categorias denotadoras da não incorporação dos papéis a partir do ECA, prevalecendo modelos de políticas remanescentes ao código de menores, de caráter mais punitivo do que de protagonismo.

Há superposição de funções entre as entidades considerando-se os eixos do sistema de garantias (promoção, defesa e controle social). Há OG fazendo acompanhamento jurídico, monitoramento de políticas e controle social, ações que se aplicam aos Conselhos e às ONGs. Há superposição até entre eixos de atuação dentro das entidades que têm função de Estado, como, por exemplo, entidades que são da assistência ou do sistema de Justiça que desenvolvem escolarização.

As ONGs definiram a sua atuação de forma mais nítida e de modo a indicar um fio condutor, com papéis mais nítidos, dentro do sistema de garantias, voltados para crianças e adolescentes em situação de risco, tais como trabalho educativo, informativo e formativo. Pode-se inferir que as suas ações estejam dentro do papel mobilizador e articulador. Não há também nas ONGs a demarcação da atuação do psicólogo a partir do modelo clínico que aparece nos outros tipos de entidades. Todavia, para quaisquer das entidades, não há, para a atuação do 
psicólogo, a exigência de uma especialidade, ou seja, as ações podem ser executadas por psicólogos de várias áreas da Psicologia.

É possível vislumbrar que, no conjunto, as entidades participantes desenvolvem as atividades do sistema de garantias de direito: promoção, defesa e controle; todavia, elas não o fazem enquanto rede, e não estão fazendo aquilo que seria específico do seu eixo de atuação preconizado pelo sistema de garantias (promoção, defesa e controle). Os dados revelam que há instituições que desenvolvem ações que seriam da responsabilidade de outrem.

Embora todas tenham como objetivos viabilizar os direitos de crianças e adolescentes, há ainda a reprodução de práticas antiquadas, principalmente no papel do psicólogo, do Código de 1927, da situação irregular e das políticas assistenciais que emergem também nesses dados, políticas e práticas essas consubstanciadas na velha cultura do disciplinamento de jovens pobres, expressas quer na profissionalização, quer no acompanhamento de medidas, quer nos aspectos sexuais, que aqui aparecem não como educação sexual, mas como planejamento familiar. Tal fato revela, por outro lado, que a atuação do psicólogo nas entidades de atendimento a crianças e adolescentes em situação de risco dar-se-á, conforme Vieira (2003), em um espaço político, público, coletivo, viabilizador de direitos e dentro de um sistema de rede, ou seja, da complementaridade técnica. Os dados, por sua vez, revelam que, na prática, o espaço é público, mas as instituições não atuam em rede, e o papel do psicólogo ainda é o de técnico que só atua do ponto de vista do conhecimento específico, sem considerar a criança e o adolescente como sujeitos de sua história, como sujeitos de direitos, protagonistas.

As dificuldades apontadas tanto pelos gestores das entidades como pelos psicólogos relacionam-se tanto às condições de trabalho que demandam do Estado, nas três esferas (federal, estadual e municipal), maiores investimentos nas políticas públicas. Ambos apontaram ainda dificuldades oriundas da falta de comprometimento e de incorporação de responsabilidades tanto por parte da família quanto da sociedade. Os problemas pertencem, no seu conjunto, ao tripé (família, sociedade e Estado) concebido no ECA no Artigo 4o. Todavia, vê-se que, no caso da família, ela é o foco da ação, e a postura das entidades ao falar das dificuldades pertinentes a ela o fazem culpabilizando-a, e não vislumbrando-a com esse foco da ação. Nas saídas elencadas para fazer frente a essas dificuldades, concebe-se que a maior parte das saídas é de responsabilidade do Estado. No entanto, chama a atenção uma perspectiva de REDE que foi apontada pelas entidades como saída para enfrentar as dificuldades, o que pode ter vários significados, dentre os quais o de que, se o sistema de garantias ainda não funciona na prática, há a percepção por parte das entidades de que ele se faz necessário. A rede é percebida não necessariamente como metodologia de viabilização dos direitos da criança e do adolescente, mas como forma de superação das dificuldades infra-estruturais.

Há uma série de definições usadas pelas entidades para fazer referência ao trabalho do psicólogo. Não há elementos para se saber se a operacionalização também é diferente ou se se trata da mesma ação com nomes diferentes, tais como atendimento psicossocial ou acompanhamento psicossocial. Mas sobressaise, na maioria dos dados, quer quando falam os responsáveis pelas entidades, quer quando falam os próprios psicólogos, a concepção da atuação do psicólogo fundamentada no modelo clínico e individual. A atuação do psicólogo continua, em parte, pautada no modelo técnico, liberal e autônomo. Como diz Vieira (2003), o trabalho do psicólogo continua no trabalho técnico, ele (o psicólogo) não está na amplitude. É interessante observar 
que, enquanto a atuação das entidades junto às crianças e aos adolescentes em situação de risco se restringe ao atendimento assistencial, a atuação do psicólogo nesse contexto é marcadamente clínica, nos moldes reparadores do dano individual. $\mathrm{O}$ profissional não atua no âmbito do contexto, mas do indivíduo.

Quando o psicólogo fala das dificuldades encontradas na viabilização do seu trabalho, predominam as dificuldades de ordem econômica e estrutural e a descontinuidade da clientela. No primeiro caso, há repetidas referências à falta de salas para o atendimento. Infere-se que isso advenha do modelo clínico tomado como referência para a atuação do referido profissional, modelo esse que tem, dentre as suas ferramentas importantes, a necessidade de um espaço, de um setting. No segundo caso, deduz-se, a partir dos dados apresentados, que há, também por parte do psicólogo, uma compreensão e uma cobrança em relação à sua clientela, com base no modelo clínico, de enquadre do cliente, no modelo do profissional liberal. Em ambos os casos, vão de encontro ao papel do psicólogo nas políticas públicas, que é o de universalização, de analisar a situação, planejar, mobilizar, articular, promover a defesa e a responsabilização, proporcionar prevenção, inclusão social das crianças, dos adolescentes e de suas famílias e viabilizar o protagonismo juvenil.

\section{Considerações finais}

Os dados que emergem das várias categorias temáticas revelam o tipo de trabalho desenvolvido pelas entidades responsáveis pelo atendimento dos direitos de crianças e adolescentes em situação de risco assim como a atuação do psicólogo nessas entidades, mas revelam essencialmente a inconsistência entre o modelo clínico, individualizado e autônomo do psicólogo e o modelo assistencialista de atendimento das entidades. No caso do psicólogo, existe a perspectiva de uma versão individualizante, etnocêntrica, que se pretende universal, missionária e civilizadora, e que nega qualquer singularidade (Ropa, \& Duarte, 1985) ou outras formas de atribuir significados, e que vê o sujeito com uma visão patologizante.

Esse modelo clínico, individualizante, impede que o psicólogo acompanhe as novas singularidades decorrentes das mudanças e os processo de integração de diversos protagonistas, o que requer o deslocamento do psicólogo nos diversos espaços por onde transita esse sujeito familiar ou institucional (Gonzáles-Rey, 2001). Para os profissionais de Psicologia centrados nesse modelo individualizante, a não-efetividade do seu trabalho é vista pela não-adesão do paciente e pela insuficiência do espaço físico que o modelo requer, cuja eficácia para esse público-alvo não é questionada.

A psicoterapia não pode ser o modo por excelência da atuação profissional nem na atenção individual, nem no modelo do profissional liberal, o que significa que o psicólogo deve ocupar um espaço político e público, enfim, em que se possam compreender os processos de subjetivação tais como se produzem na sociedade brasileira e o diálogo com as referências teóricas conectadas a essa realidade (Conselho Federal de Psicologia, 2003). Isso significa que o profissional de Psicologia que trabalha nas entidades que atendem crianças e adolescentes em situação de risco deve entender e atuar sob a perspectiva de que a criança e o adolescente são sujeitos que precisam das políticas sociais básicas a fim de ter garantida a proteção integral, fundamental para o seu desenvolvimento. 


\section{Maria de Fátima Pereira Alberto*}

Doutora, professora do Departamento de Psicologia da UFPB, do Programa de Pós-Graduação em Psicologia Social da UFPB, pesquisadora do Grupo de Pesquisa Subjetividade e Trabalho e coordenadora do Grupo de Estudos sobre o Trabalho Precoce/UFPB

\section{Daniela Rodrigues de Almeida, Luciana Chacon Dória, Priscylla Cavalcanti Guedes,}

\section{Tâmara Ramalho de Sousa}

Alunas do Curso de Graduação em Psicologia da UFPB

\section{Wilker Luiz Pessoa de França}

Aluno do Curso de Graduação em Psicologia da UFPB

\section{* Endereço para envio de correspondência:}

Rua Sebastião Interaminenese, 369, Edifício Porto Lugano, ap. 202, Bairro do Bessa, João Pessoa-PB.

E-mail: jfalberto@uol.com.br

Recebido 03/10/2007 Reformulado 23/07/2008 Aprovado 24/07/2008

\section{Referências}

Alberto, M. F. P. (2002). Dimensões subjetivas do trabalho precoce de meninos em condição de rua em João Pessoa (PB). Tese de Doutorado em Sociologia, Universidade Federal de Pernambuco, Recife.

Bardin, L. (1977). Análise de conteúdo. São Paulo: Martins Fontes.

Bock, A. M. B. (2003). Psicologia e o compromisso social. São Paulo: Cortez

Cabral, E. A. (1999). Sistema de garantia de direitos: um caminho para a promoção integral. Recife: CENDHEC.

Cassab, M. A. T. (2001). Jovens pobres e o futuro: a construção da subjetividade na instabilidade e incerteza. Niterói, RJ: Intertexto.

Conselho Federal de Psicologia. (2003). Relatório do /l Seminário Nacional de Psicologia e Políticas Públicas. Políticas Públicas, Psicologia e Protagonismo Social. João Pessoa: Conselho Federal de Psicologia.

Conselho Nacional dos Direitos da Criança e do Adolescente. (2000). Diretrizes Nacionais para a Política de Atenção Integral à Infância e à Adolescência. Brasília. Recuperado em abril de 2007, de www.mj.gov.br/sedh/conanda

Costa, A. C. G. (1990). Participar é preciso. Ministério da Ação Social, Centro Brasileiro para a Infância e Adolescência (CBIA). Rio de Janeiro: Bloch.

Góes, J. R., \& Florentino, M. (2002). Crianças escravas, crianças dos escravos. In M. Del Priore (Org.), Histórias das crianças no Brasil (pp. 177-191). São Paulo: Contexto.

González-Rey, F. L. (2001). O enfoque histórico-cultural e seu sentido para a psicologia clínica: uma reflexão. In A. M. B. Bock, M. G. M. Gonçalves, \& O. Furtado (Orgs.), Psicologia sócio-histórica: uma perspectiva crítica em Psicologia (pp. 193-214). São Paulo: Cortez.

Guattarri, S., \& Rolnik, S. (1986). Micropolítica: cartografias do desejo. Petrópolis, RJ: Vozes.

Guérin, F., Laville, A., Daniellou, F., Duraffourg, J., Kerguelen, A. (1991). Comprendre le travail pour le tranformer: la pratique de I'ergonomie. Paris: Anact.

Horowitz, F. D. (1992). The concept of risk: A reevaluation. In S. L. Friedman \& M. D. Sigman (Eds.), The psychological developmental of birthweight children (pp. 61-88). Norwood: Ablex.

Lescher, A. D. (2004). Crianças em situação de risco social: limites e necessidades da atuação do profissional de saúde. Recuperado em em abril de 2007, de www.projetoquixote. epm.br
Londoño, F. T. (1991). A origem do conceito menor. In M. Del Priore (Org.), A História da criança no Brasil (pp. 129-145). São Paulo: Cortez.

Mannheim, K. (1968). O problema da juventude na sociedade moderna. In S. Britto (Org.), Sociologia da juventude I: da Europa de Marx à América Latina de hoje (pp. 69-94). Rio de Janeiro: Zahar.

Ministério do Desenvolvimento Social. Secretaria Nacional de Assistência Social. (2004). Política Nacional de Assistência Social. Brasília, DF: MDS/Governo Federal.

Ministério da Previdência e Assistência Social. (2001). LOAS: Lei Orgânica da Assistência Social (2a ed.). Brasília, DF: SEAS.

Pilotti, F. (1995). Crise e perspectivas da assistência à infância na América Latina. In F. Pilotti \& I. Rizzini (Orgs.), A arte de governar crianças: a história das políticas sociais, da legislação e da assistência à infância no Brasil (pp. 11-45). Rio de Janeiro: Ed. Universitária Santa Úrsula; Amais Livraria e Editora.

Ramos, F. P. (2002). A história trágico-marítima das crianças nas embarcações portuguesas do século XVI. In M. Del Priore (Org.), Histórias das crianças no Brasil (pp. 19-54). São Paulo: Contexto.

Ropa, D., \& Duarte, L. F. D. (1985). Considerações teóricas sobre a questão do atendimento psicológico às classes trabalhadoras. In S. A. Figueira (Org), Cultura da psicanálise (pp. 179-201). São Paulo: Brasiliense.

Santos, M. A. C. (2002). Criança e criminalidade no início do século. In M. Del Priore, (Org.), História das crianças no Brasil (pp. 210-230). São Paulo: Contexto.

Teixeira, C. L., \& Novaes, E. B. (2004). Acompanhamento psicossocial de adolescentes: Uma metodologia inovadora no enfrentamento da exploração sexual. In R. M. C. Libório \& S. M. G. Souza (Orgs.), A exploração sexual de crianças e adolescentes no Brasil (pp. 293-317). São Paulo: Casa do Psicólogo.

Venâncio, R. P. (2002). Os aprendizes da guerra. In M. Del Priore, (Org.), História das crianças no Brasil (pp. 192-209). São Paulo: Contexto.

Vieira, C. (2003). Protagonismo social da psicologia na área da criança e do adolescente In Conselho Federal de Psicologia, Relatório do II Seminário Nacional de Psicologia e Políticas Públicas. Políticas Públicas, Psicologia e Protagonismo Social. João Pessoa. 